\title{
Budget impact of secondary hyperparathyroidism treatment in chronic kidney disease in an Ecuadorian social security hospital
}

Luis Manjarres ${ }^{1}$, Pilar Sanchez ${ }^{1}$, María C. Cabezas ${ }^{2,4^{*}}$, Marco Fornasini ${ }^{3}$, Valeria Freire ${ }^{2}$ and Adelin Albert ${ }^{5}$

\begin{abstract}
Background: Chronic kidney disease (CKD) is a disorder with high morbidity and mortality worldwide whose complications generate multiple costs. In Ecuador, only a few healthcare institutions have implemented management protocols aimed to reduce costs and to improve the quality of life of patients. The aim of this study is to evaluate the short-term (1-year) and long-term (5-year) costs and savings in the management of secondary hyperparathyroidism (SHPT) of hemodialyzed CKD patients by comparing calcitriol and paricalcitol in a large social security hospital in Quito, Ecuador.

Methods: The estimation model assessed the resources used in the management of SHPT by comparing prospectively the cost savings within 1-year and 5-year time horizon with calcitriol and paricalcitol. Hospitalization, erythropoietin (EPO), treatment doses, intravenous iron consumption, and medical supplies were estimated according international references, based on the initial parathormone level (iPTH) of patients. The Ecuadorian National Reference costs (2014-2015) and institutional costs were used to calculate treatment costs. A statistical sensitivity analysis was also performed.

Results: The study was based on data from 354 patients of whom $147(41.4 \%)$ had a value of iPTH in the range $300-600 \mathrm{pg} / \mathrm{ml}, 45$ (12.8\%) in the range $601-800 \mathrm{pg} / \mathrm{ml}$, and 162 (45.7\%) over $800 \mathrm{pg} / \mathrm{ml}$. The 1-year estimated costs per patient for calcitriol and paricalcitol, respectively, were: medication, 63.88 USD and 1,123.44 USD; EPO, 19,522.95 USD and 16,478 USD; intravenous iron 143.21 USD and 187.76 USD. Yearly hospitalization costs per patient were 11,647.99 USD with calcitriol and 8,019.41 USD with paricalcitol. Total yearly costs per patient amounted to 31,378.02 USD with calcitriol and 25,809.50 USD with paricalcitol. Total savings using paricalcitol were 5,568.52 USD per patient compared with calcitriol. The 5-year cumulative medication costs were 319 USD for calcitriol and 2,403 USD for paricalcitol; EPO with calcitriol was 97,615 USD and with paricalcitol 82,394 USD; intravenous iron with calcitriol was 716 USD and paricalcitol 939 USD. Hospitalization costs for patients with calcitriol and paricalcitol were 43,095 USD and 62,595 USD, respectively. Total savings using paricalcitol amounted 32,414 USD per patient compared with calcitriol.
\end{abstract}

Conclusions: Paricalcitol use generated more cost savings than calcitriol after 1 and 5 years.

Keywords: Renal kidney disease, Calcitriol, Paricalcitol

\footnotetext{
* Correspondence: maria.cabezas@hrservicesec.com

${ }^{2}$ Medical School, Pontifical Catholic University of Ecuador, Quito, Ecuador

${ }^{4}$ Health \& Research Services, Quito, Ecuador

Full list of author information is available at the end of the article
} 


\section{Background}

Chronic kidney disease (CKD) is a clinical condition, which affects approximately $10 \%$ of the adult population with high morbidity and mortality worldwide $[1,2]$. According to the Vivenkanad study in 2013, the overall prevalence of CKD ranged between 8 and $16 \%$. The same study reported that in Latin America, the prevalence increased by about $7 \%$ during the last few years [3]. The increasing frequency of type II diabetes and hypertension have greatly contributed to increased prevalence of CKD $[4,5]$.

A common complication of CKD is secondary hyperparathyroidism (SHPT), which generates high treatment costs. SHPT increases the frequency of skeletal and cardiovascular disorders [6]. SHPT is also known to worsen renal-driven anemia because higher levels of circulating parathyroid hormone is associated with a lower response to recombinant human erythropoietin [7]. Furthermore, SHPT is associated with increased hospitalization rates, especially when parathormone (PTH) levels exceed $600 \mathrm{pg} / \mathrm{ml}$ [8]. Thus, SHPT generates high costs to healthcare systems [9].

An Argentinian study published in 2013 reported that among 1210 CKD hemodialyzed patients, $26.7 \%$ had an initial parathyroid hormone $(\mathrm{iPTH})>300 \mathrm{pg} / \mathrm{ml}$ [3]. In Ecuador, the total number of SHTP cases is not known; however, several studies based on relatively small samples have exhibited differing prevalence levels. As an illustration, a study (88 patients) in Guayaquil, Ecuador reported $3.4 \%$ of SPTH cases in dialysis patients in 2009 [10], while another study (2012), in Ambato, Ecuador, on 54 hemodialyzed patients with CKD reported $32 \%$ of the population with values $>450 \mathrm{pg} / \mathrm{ml}$ of iPTH [11].

The cost of care for CKD is high, especially in end stage renal disease (ESRD). In England (2012), the cost of CKD in 2009-2010 was estimated at $£ 1.44$ to $£ 1.45$ billion [12, 13]. Patients with ESRD consumed important economic resources from healthcare systems, with an estimated annual cost of 41,341.05 USD [14, 15]. Moreover, costs of CKD treatment have been increasing steadily; for example in the United States, they grew by $57 \%$ between 1999 and 2004 [16]. In Latin American countries, the costs range from 10,956 USD to 14,654 USD per year per patient [17].

Calcitriol has been considered to be the first choice drug for treating SHPT in ESRD [18]. It is effective and inexpensive, although its use is frequently limited for patients with either hypercalcemia or hypophosphatemia. Other drugs like paricalcitol have been developed to treat these conditions [18]. Unlike calcitriol, paricalcitol has minimal impact on serum calcium and phosphorus [9]. However, paricalcitol is much more expensive than calcitriol. In Colombia (2016), the price of one vial of paricalcitol $(5 \mu \mathrm{g})$ is 79,400 Colombian pesos (26.46 USD), while $0.25 \mu \mathrm{g}$ of calcitriol costs
5,018 Colombian pesos (1.67 USD), reflecting the higher cost of paricalcitol, according to the Colombian Ministry of Health [19]. In Ecuador (2016), the price of paricalcitol is greater than calcitriol according the price of one vial of paricalcitol is $31.25 \mathrm{USD}$, while $0.25 \mu \mathrm{g}$ of calcitriol costs 0.21 USD according the Ecuadorian Social Security Institute [20].

The aim of this comparative study was to evaluate the budget impact associated with calcitriol and paricalcitol in the management of secondary hyperparathyroidism (SHPT) in hemodialyzed patients with chronic kidney disease (CKD) 1-year and 5-year time horizons.

\section{Methods}

The budget impact model was developed in Microsoft Excel to calculate the costs of management of hemodialyzed patients hospitalized with SHPT due to chronic kidney disease in a social security hospital in Quito, Ecuador. The study included data of patients from the nephrology department with a diagnosis of SHPT, who were under dialysis treatment between September 2013 and October 2014. Eligible patients were identified using code E21.1 of the International Classification of Diseases (ICD-10) for SHPT.

The only inclusion criterion was that the patient had been under SHPT dialysis treatment with either paricalcitol or calcitriol. Data collection consisted of a retrospective chart review of the institutional database. Serum iPTH was recorded during the previous 12 months in patients with calcitriol and paricalcitol treatment.

The study developed a model to estimate the annual cost of paricalcitol and calcitriol treatment. The analysis used international studies published to calculate the costs of management and treatment. We implemented an estimation to calculate the impact budget over 1 year and 5-year periods.

\section{Literature review}

A systematic search was conducted in PubMed and Medline database in order to identify all randomized clinical trials of SHPT treatment, particularly those that compared paricalcitol and calcitriol treatments with respect to efficacy and which were conducted between January 2004 and December 2013. Trial selection criteria were based on study variables such as hospitalization days, iron, and erythropoietin consumption. Paricalcitol and calcitriol doses were determined from international effectiveness trials and guidelines (see Fig. 1).

The study of Naves Diaz was the reference to classify the initial PTH level (iPTH). The study classified patient iPTH level in three groups (group I: 300-600; group II: 601-800; group III: $>800 \mathrm{pg} / \mathrm{ml}$ ) in order to determine the amount of paricalcitol required for SHPT treatment 


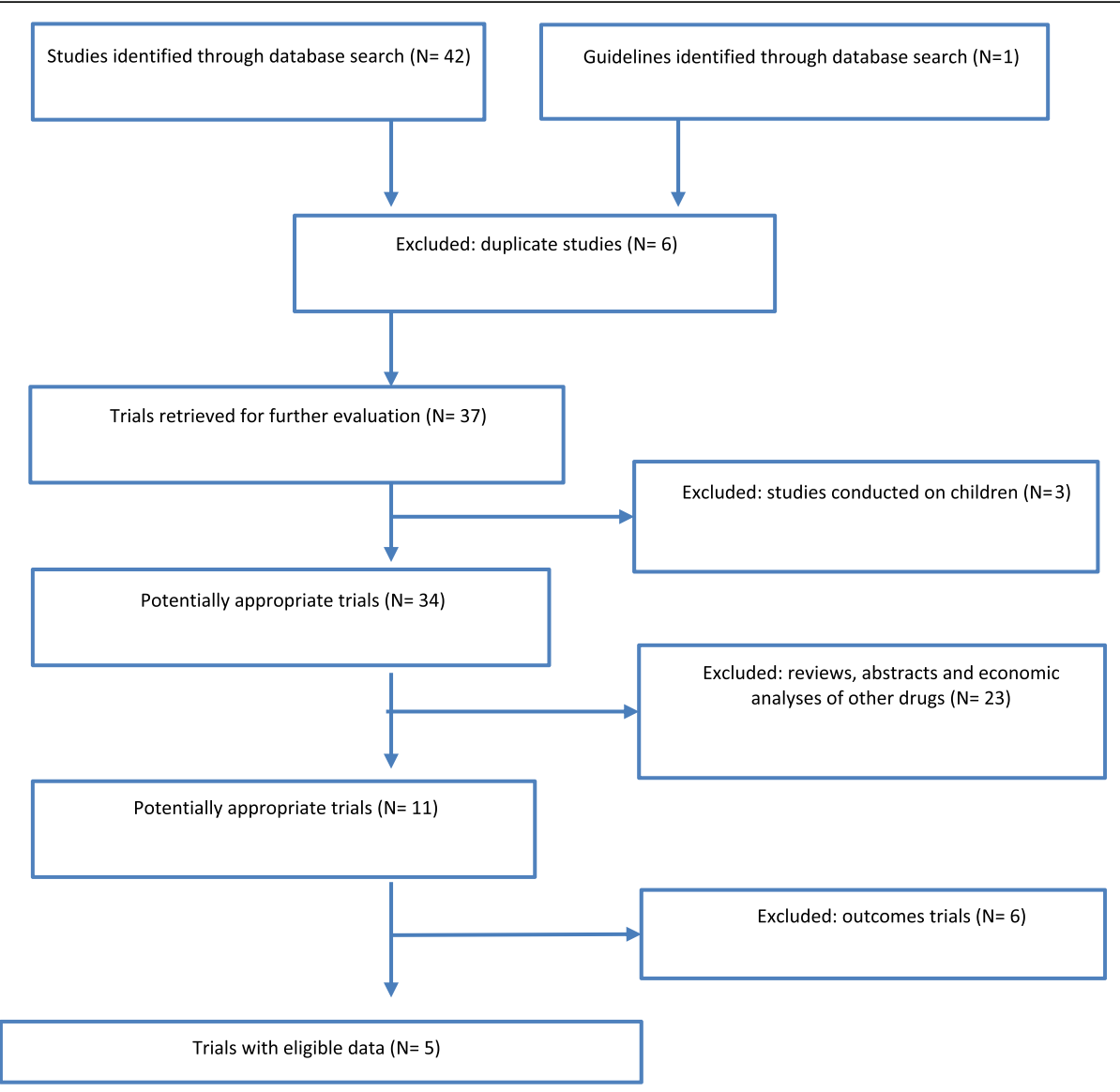

Fig. 1 Flowchart for study selection

[21]. Llach study provided the paricalcitol dose reference for group I. For groups II and III, doses were calculated based on a simple linear extrapolation [22]. The National Kidney Foundation Kidney Disease Outcomes Quality Initiative (NKF KDOQI) guidelines were the reference to determine the amount of calcitriol needed to treat SHPT. The guidelines recommend $0.25 \mu \mathrm{g}$ of calcitriol per day [23].

The Capuano study was used as the reference to determine erythropoietin and intravenous iron yearly costs. This study showed a significant difference in the use of erythropoietin when using paricalcitol versus

Table 1 Annual consumption of erythropoietin and intravenous iron according Paricalcitol and Calcitriol therapies

\begin{tabular}{lrrr}
\hline Parameter & Paricalcitol & Calcitriol & $P$-value \\
\hline Erythropoietin Weekly Average & $11,758 \mathrm{UI}$ & $13,930 \mathrm{UI}$ & $<0.05$ \\
Consumption & & & \\
$\begin{array}{l}\text { Intravenous Iron Weekly Average } \\
\text { Consumption }\end{array}$ & $59 \mathrm{mg}$ & $45 \mathrm{mg}$ & $<0.05$
\end{tabular}

Source: Capuano, A., 2009 calcitriol [24]. As shown in Table 1, there are statistically significant differences in the weekly consumption of erythropoietin and intravenous iron in patients treated with paricalcitol and calcitriol. The calculations in the study used the annual consumption for each therapy (Table 1).

Hospitalization were calculated based on the Dobrez study based on a sample of 11,443 patients, of whom 4,611 received treatment with paricalcitol and 6,832 with calcitriol [25]. The model used the averages of patients' hospitalized rates and hospitalization days for each SHPT therapy (See Table 2).

Table 2 Hospitalization rates in patients with Paricalcitol and Calcitriol

\begin{tabular}{lcc}
\hline Parameter & Paricalcitol & Calcitriol \\
\hline $\begin{array}{l}\text { Hospitalized patients per year per each 100 } \\
\text { patients in treatment }\end{array}$ & 59.6 & 75.2 \\
Average number of hospitalization days per year & 17.2 & 19.8 \\
\hline
\end{tabular}

Source: Dobrez, DG., 2004 


\section{Cost evaluation}

The cost estimation included the resources used in the management of SHPT, such as erythropoietin and intravenous iron. Other variables considered in the model were erythropoietin consumption, intravenous iron consumption, hospitalization days, and medical supplies costs that were calculated based on international references [21-25]. Treatments costs were derived from "The Ecuadorian National Reference Costs", published in December 2014 (see Table 3). Inflation was estimated from International Monetary Fund data.

The paricalcitol price was established using the databases from the institution. The study calculated the cost of $1 \mu \mathrm{g}$ for use in the model.

To calculate the annual cost of paricalcitol for each iPTH group, the model used the following formula:

$$
\begin{aligned}
& \text { Paricalcitol annual cost per PTH group } \\
& =\left[\begin{array}{c}
\text { Paricalcitol } \\
\text { micrograms } \\
\text { required per year per } \\
\text { PTH group }
\end{array}\right] \\
& \times\left[\begin{array}{c}
\text { Paricalcitol } \\
\text { micrograms price }
\end{array}\right]
\end{aligned}
$$

The average paricalcitol cost per year was used to estimate the cost per patient treatment using the following formula:

$$
\begin{aligned}
& \text { Paricalcitol cost per patient } \\
& =\Sigma\left[\begin{array}{c}
\text { Paricalcitol annual } \\
\text { costs per PTH group }
\end{array}\right] \times\left[\begin{array}{c}
\% \text { patients } \\
\text { per PTH } \\
\text { group }
\end{array}\right]
\end{aligned}
$$

For calcitriol, the model considered the different presentations and the institutional price to estimate the drug cost per microgram.

Annual costs of calcitriol treatment per patient in the model were calculated using the following formula:

$$
\begin{aligned}
& \text { Calcitriol annual cost per patient } \\
& =\left[\begin{array}{c}
\text { Calciotriol dose } \\
0,25 \mu g
\end{array}\right] \times\left[\begin{array}{c}
\mu g \text { Calcitriol } \\
\text { Price }
\end{array}\right] \\
& \quad \times\left[\begin{array}{c}
365 \\
\text { days }
\end{array}\right]
\end{aligned}
$$

Erythropoietin was calculated based on 1 International Unit (IU) of cost according the institutional cost of

Table 3 Unit cost according the National Reference

\begin{tabular}{lr}
\hline Category & USD \\
\hline Paricalcitol $1 \mu \mathrm{g}$ & 1.25 \\
Calcitriol $1 \mu \mathrm{g}$ & 0.84 \\
Hospitalization Day & 116.76 \\
Erythropoietin 1 UI & 0.03 \\
Iron $1 \mathrm{mg}$ & 0.06 \\
\hline
\end{tabular}

erythropoietin. The annual cost of erythropoietin was calculated by multiplying the mean unit cost by the weekly consumption of erythropoietin and then multiplying by 52 weeks.

The cost of annual intravenous iron was calculated based on its institutional cost multiplied by weekly consumption and then multiplied by 52 weeks.

Hospitalization cost per patient was based on the price of 1 day of hospitalization according the "Ecuadorian National Reference Costs" including estimate the annual inflation.

Calculations were based on a simple linear extrapolation according the iPTH level and the literature review. Subjects with missing data were not included in the analysis.

A one-way sensitivity analysis was conducted by varying the following parameters by $\pm 10 \%$, hospitalization costs per day, average erythropoietin costs, average intravenous iron costs, treatment $\mathrm{iPTH}$, hospitalization rate reduction, annual hospitalization reduction, erythropoietin weekly savings costs of paricalcitol and calcitriol, and the number of hemodialysis per month; an inflation rate by $\pm 2.5 \%$ was included.

\section{Results}

The study was based on data from 354 SHPT patients whose iPTH levels were registered. The average estimates presented in Table 4 were calculated according to the Naves-Diaz study, divided into three iPTH 1 groups achieving, respectively, $435 \mathrm{pg} / \mathrm{ml}$ in the first group, $668 \mathrm{pg} / \mathrm{ml}$ in the second group, and $1236 \mathrm{pg} / \mathrm{ml}$ in the third group.

\section{Secondary hyperthyroidism costs}

The projected cost per patient to treat SHPT using paricalcitol across time was 1,123.44 USD the first year and 2,403 USD the fifth year. The cost for calcitriol treatment was 63.88 USD the first year, and 319 USD the fifth year, as shown in Table 5 .

Hence, treatment with paricalcitol represented costs reductions of 5,568.52 USD the first year and 32,414.00 USD the fifth year (Fig. 2).

\section{Sensitivity analyses}

The results of the one-way sensitivity analyses are shown in Table 6. The present model yielded a decrease around

Table 4 Initial PTH levels ( $n=354$ patients)

\begin{tabular}{cccc}
\hline & Basal PTH group & No. of patients & $\begin{array}{c}\text { PTH mean level } \\
(\mathrm{pg} / \mathrm{ml})\end{array}$ \\
\hline PTH serum levels & $300-600 \mathrm{pg} / \mathrm{ml}$ & 118 & 435 \\
& $601-800 \mathrm{pg} / \mathrm{ml}$ & 67 & 668 \\
& $>800 \mathrm{pg} / \mathrm{ml}$ & 169 & 1,236 \\
\hline
\end{tabular}

${ }^{\mathrm{a}}$ Basal PTH ranges were according Naves-Diaz Study [21] 
Table 5 Cumulative costs per patient short and long term in USD

\begin{tabular}{|c|c|c|c|c|}
\hline & \multicolumn{2}{|l|}{ 1st Year } & \multicolumn{2}{|l|}{ 5th Year } \\
\hline & Paricalcitol & Calcitriol & Paricalcitol & Calcitrio \\
\hline & (A) & (B) & (A) & (B) \\
\hline SHPT treatment & $1,123.44$ & 63.88 & 2,403 & 319 \\
\hline Erythropoietin & 16,478 & $19,522.95$ & 82,394 & 97,615 \\
\hline Intravenous iron & 187.76 & 143.21 & 939 & 716 \\
\hline Hospitalization & $8,019.41$ & $11,647.99$ & 43,095 & 62,595 \\
\hline Total & $25,809.50$ & $31,378.02$ & 128,831 & 161,245 \\
\hline
\end{tabular}

$18 \%$ of costs in all parameters. Sensitivity analysis shown that the average treatment of SHPT with paricalcitol was less expensive than that of calcitriol.

\section{Discussion}

This study shows that paricalcitol was the best economic option to treat patients with SHPT, saving 2,679.31 USD in 1 year and 16,249 USD in 5 years per patient treated. Treatment costs with paricalcitol were 18,799 USD for the short term (1-year) and 91,744 USD for the long term (5-year). Despite its higher costs compared with calcitriol, paricalcitol showed higher effectiveness and benefits. Patients treated with paricalcitol presented fewer hospitalizations (59.6\%), generating important savings in direct costs in the management of patients with SHPT.

According to the study of Nuijten et al. (2009) conducted in the United States, treatment with paricalcitol represented annual savings of 1,941 USD compared to calcitriol [26]. This results of that study are similar to those presented here, where paricalcitol savings per patient/year were 2,679.31 USD in the short term (1-year). The study published by Lorenzoni et al. (2014) demonstrated that paricalcitol used during the pre-dialysis stage and at early stage of SHPT in Italy represented an overall reduction in direct medical costs from 1'782,921 to 1'622,357 Euro for the healthcare system. The savings in a hypothetical cohort of 1,000 patients would amount to $1^{\prime} 971,500$ Euro, which is less than the savings per 1,000 patients of $16^{\prime} 249,000$ USD calculated in our model [27]. However, Lorenzoni study was implemented in pre-dialysis stage.

Another study, conducted in Mexico by SanchezCasillas et al. (2013), reported a total long term (5-year) cost of 24,532.88 USD using paricalcitol therapy compared to 35,633.36 USD using calcitriol therapy, which reflects greater costs for both therapies compared to those calculated in our study $(91,744$ USD vs 107,933 USD) [28]. Nevertheless, the Mexican study also found cost savings of paricalcitol compared with calcitriol in SHPT.

The work of Sprague et al. (2003) in the United States demonstrated that paricalcitol is more effective over PTH levels in SHPT patients, achieving a reduction of iPTH levels over $50 \%$ after 18 weeks of treatment with less sustained hypercalcemia [29]. The control of serum calcium in SHPT patients is important for avoiding cardiovascular complications and parathyroid hyperplasia, thus leading to fewer hospitalizations, as described in the 2006 Cheng et al. review [30]. A study by Rosery et

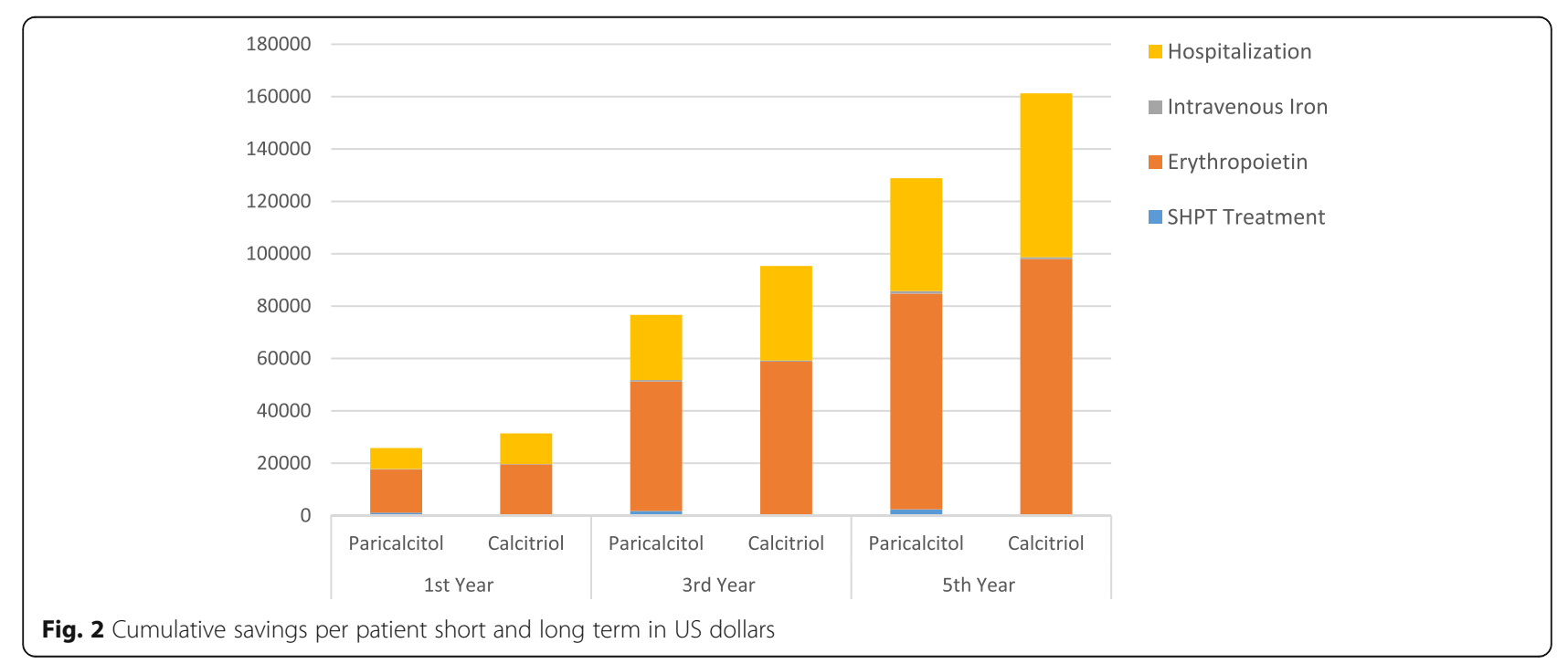


Table 6 Cumulative Net Savings in 5 years

\begin{tabular}{|c|c|c|c|}
\hline \multirow[b]{2}{*}{ Parameter } & \multirow[b]{2}{*}{ Minimum savings (USD) } & \multicolumn{2}{|l|}{ 5-year savings } \\
\hline & & Maximum savings (USD) & Initial value (USD) \\
\hline Daily hospitalization costs ( $\pm 10 \%)$ & 52,427 & 80,178 & 66,303 \\
\hline Erythropoietin costs ( $\pm 10 \%)$ & 61,389 & 72,683 & 66,303 \\
\hline Intravenous iron costs ( $\pm 10 \%)$ & 66,214 & 66,391 & 66,303 \\
\hline Annual inflation 2014-2016 ( $\pm 2.5 \%)$ & 56,397 & 76,876 & 66,303 \\
\hline Treatment costs per iPTH group (I: $29 \%$, II: $17 \%$, III: 42 \%) & 66,303 & 89,994 & 66,303 \\
\hline Hemodialysis per month ( $\pm 10 \%)$ & 79.66 & 52,983 & 66,303 \\
\hline Weekly savings erythropoietin administration ( $\pm 10 \%)$ & 60,164 & 72,435 & 66,303 \\
\hline Hospitalization rate reduction ( $\pm 10 \%)$ & 58,276 & 74,329 & 66,303 \\
\hline Annual hospitalization reduction ( $\pm 10 \%)$ & 61,667 & 70,938 & 66,303 \\
\hline
\end{tabular}

al. (2006) conducted in 6376 patients indicated that paricalcitol treatment resulted in a reduction of $84 \%$ of hospitalizations in 1 year compared to calcitriol treatment, producing savings of 5,394 USD associated with paricalcitol treatment [31]. In sum, these studies demonstrated the cost savings of paricalcitol consistent with the present study.

In our model, erythropoietin was the most expensive medication used in the management of SHPT patients. Capuano et al. described the erythropoietin international units recommended for patients treated with paricalcitol compared with calcitriol. They showed that there is evidence of a need of lower amount of erythropoietin with paricalcitol therapy [24]. Afsar et al. and Riccio et al. (2015) showed that paricalcitol increased hemoglobin levels, decreased urinary protein excretion, and generated lower resistance to erythropoietin treatment; in addition, it did not interfere with erythropoietin synthesis [32, 33].

The present study has some limitations, most importantly, that the study population was limited to the main social security general hospital in Quito, Ecuador. Another limitation is that the study was not able to compare the cost of paricalcitol with calcinanet, which is not available in the Ecuadorian market. In addition, our model did not take into account the CKD stage of disease only the iPTH. Finally, the model was developed using economic simulations based on international parameters, which might not be applicable in Ecuador.

\section{Conclusions}

In conclusion, the average annual cost per patient for paricalcitol therapy was 18,799 , USD of which $80 \%$ represented hospitalization and erythropoietin consumption. The use of paricalcitol, according to PTH initial level, represented substantial economic savings of 2,679 USD in the first year and 16,249 USD in the fifth year, when compared to calcitriol. The present study supports the use of paricalcitol as the first choice drug to treat SHPT in patients with chronic renal insufficiency.

\section{Abbreviations}

CKD: Chronic kidney disease; EPO: Erythropoietin; ESRD: End stage renal disease; ICD-10: International classification of diseases; iPTH: Initial parathormone; IU: International Unit; NKF KDOQI: National kidney foundation kidney disease outcomes quality initiative (NKF KDOQI); PTH: Parathormone; SHPT: Secondary hyperparathyroidism (SHPT)

\section{Acknowledgments}

We wish to thank Professor Will Watters and MS. Jennifer Mullin for their assistance with the critical review of the document.

\section{Funding}

The project was supported by Abbvie Ecuador laboratories and paper publication was sponsored by Pontifical Catholic University of Ecuador and Universidad de las Américas.

\section{Availability of data and materials}

Erythropoietin consumption, intravenous iron consumption, hospitalization days, and medical supplies costs were calculated based on international references included in the present manuscript. Treatments costs were derived from "The Ecuadorian National Reference Costs" and inflation was estimated from data of the International Monetary Fund.

\section{Authors' contributions}

LM carried out and supervised the design, implementation, and acquisition of data in the study. PS was involved in revising the manuscript for important intellectual content. MC carried out the design, implementation, and acquisition of data used in the study. MF was involved in revising the manuscript for important intellectual content. VF was involved in the project implementation and acquisition of data. AA was involved in revising the manuscript critically for important intellectual content. All authors read and approved the final manuscript.

\section{Authors' information}

Luis Manjarres is an MD with a specialization in nephrology and is chief of nephrology service at Carlos Andrade Marin Hospital in Quito, Ecuador. Pilar Sanchez is an MD with a specialization in nephrology. She is the chief of the dialysis service at Carlos Andrade Marin Hospital in Quito, Ecuador. Maria de Carmen Cabezas is MD and PhD. She is a researcher at the School of Medicine, Pontifical Catholic University of Ecuador in Quito, Ecuador. Marco Fornasini is MD and PhD. He is a full time professor and researcher at the Universidad de las Americas. Quito, Ecuador; his expertise is in the epidemiology of chronic diseases and infectious diseases.

Valeria Freire is MD (c) at the School of Medicine of the Pontifical Catholic University of Ecuador. Quito, Ecuador.

Adelin Albert, PhD, is professor emeritus of medical informatics and biostatistics, Department of Public Health, University of Liège, Liège, Belgium. 


\section{Consent for publication}

Not applicable. The study was an economic simulation.

\section{Ethics approval and consent to participate}

Not applicable. The study was an economic simulation.

\section{Author details}

${ }^{1}$ Nephrology Service, Carlos Andrade Marin Hospital, Quito, Ecuador. ${ }^{2}$ Medical School, Pontifical Catholic University of Ecuador, Quito, Ecuador. ${ }^{3}$ Translational Research Center, Universidad de las Américas (UDLA), Quito, Ecuador. ${ }^{4}$ Health \& Research Services, Quito, Ecuador. ${ }^{5}$ Public Health Department, University of Liège, Liège, Belgium.

Received: 2 April 2016 Accepted: 15 August 2016

\section{Published online: 26 August 2016}

\section{References}

1. Braun L, Sood V, Hogue S, Lieberman B, Copley-Merriman C. High burden and unmet patient needs in chronic kidney disease. Int J Nephrol Renovasc Dis. 2012;5:151-63.

2. Stengel B, Combe C, Jacquelinet C, Briancon S, Fouque D, Laville M, Frimat L, Pascal C, Herpe YE, Deleuze JF, et al. The French Chronic Kidney DiseaseRenal Epidemiology and Information Network (CKD-REIN) cohort study. Nephrol Dial Transplant. 2014;29(8):1500-7.

3. Jha V, Garcia-Garcia G, Iseki K, Li Z, Naicker S, Plattner B, Saran R, Wang AY, Yang CW. Chronic kidney disease: global dimension and perspectives. Lancet. 2013;382(9888):260-72.

4. Cusumano AM, Gonzalez Bedat MC. Chronic kidney disease in Latin America: time to improve screening and detection. Clin J Am Soc Nephrol. 2008:3(2):594-600

5. Singh AK, Farag YM, Mittal BV, Subramanian KK, Reddy SR, Acharya VN, Almeida AF, Channakeshavamurthy A, Ballal HS PG, et al. Epidemiology and risk factors of chronic kidney disease in India-results from the SEEK (Screening and Early Evaluation of Kidney Disease) study. BMC Nephrol. 2013;14:114

6. Thomas R, Kanso A, Sedor JR. Chronic kidney disease and its complications. Prim Care. 2008;35(2):329-44. vii.

7. Drueke TB, Eckardt KU. Role of secondary hyperparathyroidism in erythropoietin resistance of chronic renal failure patients. Nephrol Dial Transplant. 2002;17 Suppl 5:28-31.

8. Block GA, Klassen PS, Lazarus JM, Ofsthun N, Lowrie EG, Chertow GM Mineral metabolism, mortality, and morbidity in maintenance hemodialysis. J Am Soc Nephrol. 2004;15(8):2208-18.

9. Joy MS, Karagiannis PC, Peyerl FW. Outcomes of secondary hyperparathyroidism in chronic kidney disease and the direct costs of treatment. J Manag Care Pharm. 2007;13(5):397-411.

10. Ramirez J. PREVALENCIA DE HIPERPARATIROIDISMO SECUNDARIO EN PACIENTES SOMETIDOS A HEMODIÁLISIS" CENTRO DE DIALISIS "DR. CARLOS ELIZALDE MONTEVERDE". Guayaquil: UNIVERSIDAD DE GUAYAQUIL; 2010.

11. Tapia M. EFECTOS COLATERALES POR LA DISMINUCIÓN DEL CALCIO EN PACIENTES CON INSUFICIENCIA RENAL CRÓNICA ATENDIDOS EN LA UNIDAD RENAL CONTIGO DE LA CIUDAD DE LATACUNGA EN EL PERIODO OCTUBRE 2011-FEBRERO 2012. Ambato: Universidad Técnica de Ambato; 2012.

12. St Peter WL, Khan SS, Ebben JP, Pereira BJ, Collins AJ. Chronic kidney disease: the distribution of health care dollars. Kidney Int. 2004;66(1):313-21.

13. Kerr M, Bray B, Medcalf J, O'Donoghue DJ, Matthews B. Estimating the financial cost of chronic kidney disease to the NHS in England. Nephrol Dial Transplant. 2012:27(3):iii73-80.

14. Zhang QL, Rothenbacher D. Prevalence of chronic kidney disease in population-based studies: systematic review. BMC Public Health. 2008:8:117.

15. Rodriguez-Iturbe B, Bellorin-Font E. End-stage renal disease prevention strategies in Latin America. Kidney Int Suppl. 2005;98:S30-36.

16. Foley RN, Collins AJ. End-stage renal disease in the United States: an update from the United States Renal Data System. J Am Soc Nephrol. 2007;18(10): 2644-8.

17. Pecoits-Filho $R$, Campos $C$, Cerdas-Calderon $M$, Fortes $P$, Jarpa $C$, Just $P$, Luconi P, Lugon JR, Pacheco A, Paniagua $R$, et al. Policies and health care financing issues for dialysis in Latin America: extracts from the roundtable discussion on the economics of dialysis and chronic kidney disease. Perit Dial Int. 2009;29 Suppl 2:S222-226.
18. Bolasco P. Treatment options of secondary hyperparathyroidism (SHPT) in patients with chronic kidney disease stages 3 and 4: an historic review. Clin Cases Miner Bone Metab. 2009;6(3):210-9.

19. Ministerio de Salud y Protección Social. In: Social SIdldIP, editor. SISPRO Aplicativos Misionales. Colombia: Ministerio de Salud y Protección Social; 2016.

20. Ecuador GNdIRd. Sistema Oficial de Contratación Pública. Ecuador: Ecuador GNdIRd; 2016

21. Naves-Diaz M, Passlick-Deetjen J, Guinsburg A, Marelli C, Fernandez-Martin JL, Rodriguez-Puyol D, Cannata-Andia JB. Calcium, phosphorus, PTH and death rates in a large sample of dialysis patients from Latin America. The CORES Study. Nephrol Dial Transplant. 2011:26(6):1938-47.

22. Llach F, Yudd M. Paricalcitol in dialysis patients with calcitriol-resistant secondary hyperparathyroidism. Am J Kidney Dis. 2001;38(5 Suppl 5):S45-50.

23. National Kidney F. K/DOQI clinical practice guidelines for bone metabolism and disease in chronic kidney disease. Am J Kidney Dis. 2003:42(4 Suppl 3):S1-201.

24. Capuano A, Serio V, Pota A, Memoli B, Andreucci VE. Beneficial effects of better control of secondary hyperparathyroidism with paricalcitol in chronic dialysis patients. J Nephrol. 2009;22(1):59-68

25. Dobrez DG, Mathes A, Amdahl M, Marx SE, Melnick JZ, Sprague SM. Paricalcitol-treated patients experience improved hospitalization outcomes compared with calcitriol-treated patients in real-world clinical settings. Nephrol Dial Transplant. 2004;19(5):1174-81.

26. Nuijten M, Andress DL, Marx SE, Sterz R. Chronic kidney disease Markov model comparing paricalcitol to calcitriol for secondary hyperparathyroidism: a US perspective. Curr Med Res Opin. 2009;25(5):1221-34.

27. Lorenzoni V , Pierotti F, Turchetti G. A Budget Impact Analysis (Bia) Of The Use Of Paricalcitol For The Treatment Of Secondary Hyperparathyroidism (Shpt) In End Stage Renal Disease Patients. Value Health. 2014;17(7):A467.

28. Sanchez-Casillas JL, Ramirez-Lopez-De-N MG. Long-Term Cost Comparison Between Paricalcitol and Calcitriol for the Treatment of Secondary Hyperparathyroidism in Chronic Kidney Disease in Mexico. Value Health. 2013;16(7):A688

29. Sprague SM, Llach F, Amdahl M, Taccetta C, Batlle D. Paricalcitol versus calcitriol in the treatment of secondary hyperparathyroidism. Kidney Int. 2003:63(4):1483-90.

30. Cheng S, Coyne D. Oral paricalcitol for the treatment of secondary hyperparathyroidism in chronic kidney disease. Ther Clin Risk Manag. 2006;2(3):297-301.

31. Rosery H, Bergemann R, Marx SE, Boehnke A, Melnick J, Sterz R, Williams L. Health-economic comparison of paricalcitol, calcitriol and alfacalcidol for the treatment of secondary hyperparathyroidism during haemodialysis. Clin Drug Investig. 2006;26(11):629-38.

32. Riccio E, Sabbatini M, Bruzzese D, Capuano I, Migliaccio S, Andreucci M, Pisani A. Effect of paricalcitol vs calcitriol on hemoglobin levels in chronic kidney disease patients: a randomized trial. PLoS One. 2015;10(3), e0118174.

33. Afsar B, Agca E, Turk S. Comparison of erythropoietin resistance in hemodialysis patients using calcitriol, cinacalcet, or paricalcitol. J Clin Pharmacol. 2015;55(11):1280-5.

\section{Submit your next manuscript to BioMed Central and we will help you at every step:}

- We accept pre-submission inquiries

- Our selector tool helps you to find the most relevant journal

- We provide round the clock customer support

- Convenient online submission

- Thorough peer review

- Inclusion in PubMed and all major indexing services

- Maximum visibility for your research

Submit your manuscript at www.biomedcentral.com/submit
Biomed Central 